\title{
Context and Intention in the Nigerian Army Parade Interaction
}

\author{
Toyin Ogundele ${ }^{1}$ \\ ${ }^{1}$ Department of English, Osun State College of Education, Ilesa, Nigeria \\ Correspondence: Toyin Ogundele, Department of English, Osun State College of Education, Ilesa, Nigeria. Tel: \\ 234-080-602-2440. E-mail: todele@yahoo.com
}

Received: January 8, 2015

Accepted: March 29, 2015

Online Published: June 24, 2015

doi:10.5430/elr.v4n2p66

URL: http://dx.doi.org/10.5430/elr.v4n2p66

\begin{abstract}
This study investigates the role of context in the effective production and interpretation of intentions of addressors in Army's parade interaction. Armed-Forces Remembrance Day parade of 2009, and Inter-Brigade parade competition of 2 Division Nigerian Army of 2010 constitute the data for the study. The study which is based on insight from Harnish and Bach's (1979) Mutual Contextual beliefs and Akin Odebunmi's (2006) model of Contextual Beliefs reveals two main contextual features; they are Shared Knowledge of Signals, manifesting instrument-based sound, human based sound and body language indicating action; and Shared Knowledge of Professional Heroism, instantiating instrument based sound and reverent (narrated and verbalized). The paper concludes that these contextual features constitute various beliefs acted upon by soldiers for the production and effective interpretation of verbal exchange of parade talks among Nigerian soldiers, the sharing of which are capable of facilitating access to army parade interactions in Nigeria.
\end{abstract}

Keywords: Context, Shared Knowledge, Parade interaction, 2 Division, Nigerian Army, Effective communication

\section{Introduction}

Army discourse constitutes all instances of language use by soldiers in diverse military settings to execute army-related goals and activities, including parade. Since its establishment over the years, the Army has been engaging itself in different activities that impact positively on the lives of people in the society in which language features prominently. Consequently, army contexts have attracted the attention of linguists who are interested in how language is used for some social and security services and in the achievement of military goals. However, studies on army discourse have mainly focused on the sociolinguistic features of the discourse to the neglect of the contextual features with respect to the shared knowledge revealed in those discourses. For instance, Woodward (2010) investigates the discourse of gender in the contemporary British Army. Hawry (2010) examines the review of the Red Army and Soviet Army discourse as a variety of language while Amafah (1990) examines the English language use in the Nigerian Army. As is the case in the present study, these studies are premised on the Army discourse; nevertheless, none of them has specifically addressed the aspect of the shared knowledge revealed in the discourses. This gap is filled by this paper as applied to parade interaction in the Army.

\section{Methodology}

For our data, a purposive video recorded parade interactions of some units under 2 headquarters Nigerian Army were obtained. These were added to some participant observation conducted on the interactions of some of the Nigerian Army personnel. With the assistance of some soldiers, these were transcribed and analysed using content analysis.

\section{Context: An Overview}

Context is an important variable in the understanding of linguistic words and expressions. Context has been described in several ways by scholars from linguistics, anthropology, sociology, psychology, and so on. First, it can be said to mean the totality of the environment in which a word or a text unfolds (Mey, 2001; Hasan, 1994). Adding to this view is Odebunmi (2005) who avers that context serves as the background from which the meaning of a word springs; and it is constructed in interaction as is the case among members of the Nigerian Army during parade interaction. Morley, in his own view holds that context is:

an account of all the sociological factors which constitute the background and circumstances of the text under discussion. This includes, for example, the location and time of the text, the previous events circumscribing it, the number of 
participants involved, the nature of their personalities, their status relationship in that particular situation, accompanying actions or gestures (Morley, 1985:3)

Wardaugh (1985), expressing a similar view as Morley's above, opines that context is the surrounding physical context where the language is used, (the objects there and the actions taking place), previous conversation between the participants, relevant aspects of their life histories, the general rules of behaviour the speakers obey, their assumptions about how the various bits and pieces of the word function, and so on.

The issue of context as a potent consideration to effective language production and interpretation in discourse was pioneered by Malinowski, an anthropologist (Malinowski 1923).

According to Malinowski,

...A statement, spoken in real life, is never detached from the situation in which it has been uttered...utterance and situation are bound up inextricably with each other and the context of situation is indispensable for the understanding of the words... a word without linguistic context is mere figment and stands for nothing by itself, so in reality of a spoken living tongue, the utterance has no meaning except in the context of situation (1946:307).

We can glean from the foregoing that, behind the utterance of any expression lies the circumstance and situation that leads to its production and interpretation. As such, there are expressions, used by members of the Nigerian Army, especially during parade whose meanings remain perpetually ambiguous if contextual indexes that can aid the interpretation of such expressions are not given consideration. To understand the language use in parade interaction, therefore, it becomes imperative to have adequate knowledge of its contextual features which are shared by the participants through which parade interaction progresses unhindered. Consequently, in any speech event, such as the Nigerian Army's parade interaction, there are some contextual features that interactants hold in common which are germane to effective communication; these features are the shared knowledge and beliefs that aid, and facilitate the communicative process.

These beliefs, which are at the instance of Bach and Harnish (1979), are relevant to and activated by the context of utterance or by the utterance itself which are shared or believed to be shared by the participants. It provides the means by which the hearer recognises the speaker's communicative intention and serves as the important contextual information shared by the participants that the hearer relies on, to determine the meaning of what is uttered by the speaker, and also to determine the force and content of the speaker's illocutionary act (Babatunde, 2006). This enables participants to communicate effectively in a given situation.

This view emphasises the fact that no matter how simple the linguistic choices of participants in communicative event are, if others do not share the knowledge, no meaning will be achieved; this is analogous to the linguistic presumption recognised by Harnish and Bach (1979). According to them, in a linguistic community, whenever any member utters an element of that language, the hearer, who is also a member, knows the meaning of the element as is the case of soldiers in the Nigerian Army's parade interaction. In its expanded form, Odebunmi (2006) distinguishes four types of beliefs. These are shared knowledge of subject topic; shared knowledge of word choices referents and references; shared socio-cultural experiences, previous or immediate and shared knowledge of the situation. .

Shared knowledge of subject topic is the subject of interaction, that is, what the interaction is based on, the knowledge of which enables participants to contribute without hitches, and thus gain a good knowledge and understanding of the choice of linguistic items used during discourse.

In shared socio-cultural and situational experiences, Odebunmi (2006) elucidates that, when participants have common socio-cultural, and situational experiences, interactions move on smoothly; these experiences can be a previous or an immediate one. Thus, when any of the participants in communication is confronted with a strange situation that is culturally oriented, communication will be difficult unless he is informed about the culture. This is particularly valid for non-members of the Nigerian Army who may not be able to decode the language used during parade interaction, considering the fact that they are extant from its social and cultural settings; this agrees with the view of Thomas (1995) that if socio-cultural experiences are not shared by participants in discourse, access to both the meaning of the utterance, and the force will be impossible.

Mutual knowledge of the situation of utterance is also important if comprehension of speech actions is to be achieved by the participants in a discourse. Sometimes a shared knowledge of interactants' culture must also come into play to be able to interpret utterance meaning during discourse. In this connection, a shared knowledge of the situation of 
utterance is very crucial, and this according to Odebunmi (2006:31), is "the knowledge of the events leading to the utterance."

Shared knowledge of word choices, referents and references emphasises the mutual understanding of the choice of lexical items used by interactants during discourse for the purpose of effective communication. Relating to this, Odebunmi (2006:29) states that:

If the lexical choices made in interaction are known to all the parties, no problem will occur in understanding utterances. The problem that may arise here is if one of the participants is not familiar with the words selected, and therefore cannot locate the referents or references intended.

He explicates further that, sometimes, this occurs when technical jargons, with which participants are not familiar, are introduced into discourse. Such is the situation in the Nigerian Army's parade interaction that is replete with technical jargons the knowledge of which should be shared to engender smooth interaction

\section{Analysis and Findings}

The data reveal two main contextual features in the Nigerian Army parade interaction. These are Shared Knowledge of Signals (SKSs) and Shared Knowledge of Professional Heroism (SKPH). Each of these is discussed in turn.

\subsection{Shared Knowledge of Signals (SKSs)}

This category of shared knowledge trifurcates into instrument based sound, human based sound and body language indicating action, all of which are situated predominantly in the context of the Nigerian Army's Inter-Brigade Competition as discussed below:

\subsubsection{Instrument-based Sound}

This category of Shared Knowledge of Signals is the one with which musical instrument is used to enact, and bifurcate into drum, and drum and trumpet.

The drum as a manifestation of instrument-based sound is used to relay information to the participants in the hope that they will understand one another as a result of the common belief they share in respect of the drum signal. This is facilitated by the common professional training they have received in various Nigerian Military Institutions. As such, the Band Corps assumes a shared ground projected through numerous beating of the drum, communicating various orders to the soldiers. This is equivalent to the speech signal in the Nigerian Army and is illustrated below:

\section{Excerpt 1}

Band Corps: (Beat the band once; and then continuously). Prade loook to your left and take dressing!

In the text above, the Band Corps beating of the band serves as a signal code to the soldiers on parade in the Nigerian Army. This is instantiated by the dressing activities during the Nigerian Army inter-brigade competition. In this situation, it serves as a command signal to the soldiers on parade to turn their faces to the left and dress properly. Initially, the beating of the drum is a single stroke, this is accompanied by multiple and intermittent beating of the drum. The Band Corps, charged with the responsibility of communicating instruction through the beating of drum, believe that the soldiers on parade will understand the message relayed through the sounding of the drum. This is because they share the knowledge of the signal that is related to the dressing exercise. Thus, through the drum which is beaten once, and then intermittently, the instruction (which reveals the signal, and has the speech equivalent as italicised above) is relayed to the Nigerian soldiers. The soldiers understand this because of the common knowledge of the signal that they share with the Band Corps. This enables them to respond, by adjusting their position once, and then continuously, and adjust their line-up (take dressing) to the left with their left hands in akimbo, and rifles in their right hands with their faces turn to the left side. The essence of this in the Army is to straighten their line-up.

In the Nigerian Army, the instrument-based sound is also manifested by a combination of band and trumpet as revealed in the data. Here, the shared knowledge of signal is invoked with the combined sounding of both the drum and trumpet through which the Shared Knowledge of Signal is projected. They are utilised to direct and intensify the march past embarked upon by the soldiers on parade. They also serve as impetus or energy sharper to them. The soldiers understand this as they share the knowledge of the signal with the Band Corps, and this makes them to intensify their march past.

This signal is also used when saluting a senior officer in the Army. This is revealed during the acknowledgement of the presence of the Review Officer who is the most senior commissioned officer during the parade activity as shown in the data. The following excerpt illustrates this: 


\section{Excerpt 2}

Band Corps: Intermittent relay of drum and trumpet

The excerpt above has Preseeent arms! as the speech equivalence. Consequently, the command is relayed with the use of drum and trumpet that reveal the SKS. The soldiers understand this, and respond by holding their rifles upright off the ground in front of their body while standing at attention; the Parade Commander lowers his sword as a mark of ceremonial greeting to the Review Officer who, in turn, acknowledges the salute as he shares the knowledge of the signal connected with the greeting activity going on.

\subsubsection{Human Based Sounds}

This category of Shared Knowledge of Signal, amidst other activities, is to incite a particular soldier among the soldiers taking part in parade activities apart from the real Parade Commander, into performing a designated duty. This sound which is a command signal divides into $\mathrm{Up}$ and $\mathrm{Hiz}$ as revealed in the data.

Up Signal Command is made by a soldier designated for the purpose. It can be instantiated by the presentation of officers and men (taking part in the parade) to the Review Officer by the Parade Commander. This signal can also be made during the falling out of officers, repositioning of the Parade Commander and the soldiers on parade, the delegation of authority to the Adjutant, riffle exercise and the re-appearance of the Guard Officers. Some of these instances are illustrated in the excerpts below:

\section{Excerpt 3}

Signal Sound (Up): (indicating) Fall ooout the officers!.

\section{Excerpt 4}

\section{Up Signal Command: (indicating)'tion!}

The signal sound in excerpt three, uttered by a Nigerian soldier designated for that purpose, has the potency of ordering the two guard officers to leave the men on parade, while excerpt four serves as an instruction to the Parade Commander and the soldiers on parade to be at attention. The addressor in this situation assumes a shared ground of the signal projected by $U p$ which he believes the addressees share with him; and so, does not have to result to verbal speech that is time wasting. The addressees respond to these commands through physical acts as they share the knowledge of the signal used with the addressor. Consequently, the sub-guards in excerpt 3 march out briskly while the soldiers indicated in excerpt four come to attention, stern looking, chest out with rifles held in their left hands.

\subsubsection{Hiz Signal Command}

This class of human-based sound is utilised by Nigerian soldiers to prepare the soldiers for the march past, and incite the Adjutant Warrant Officer to end the parade. The addressor uses the sound repeatedly, to command the soldiers to salute, stand at attention, turn about, and continue marching. The appropriate and prompt responses of the participants are vivid manifestations of the SKS. Additionally, the addressor also instructs the Adjutant to fall out and march to the saluting dais using the sound, Hiz. All in all, every responsive action to Hiz signal command is equivalent to the response attracted by speech signal, thereby establishing the SKS within the Nigerian Army.

\subsubsection{Body Language Indicating Action}

This is the shared knowledge that manifests through gesture and signs of various forms. As shown in the data, it is connected to the participants' knowledge of command, issued to soldiers on parade. Thus, the Adjutant Warrant Officer in the Nigerian Army issues a command to the soldiers on parade with the use of gesture and action, coupled with the display of a stern face, marches forward from the rear, turns left and halts at the centre of the parade ground, and faces the soldiers on parade. The soldiers recognise these as an indication of serious commitment to the execution of order that will follow; this makes them to brace up for the execution of that order. The fact that the information is passed and correctly interpreted by the addressees is an apt exemplary indicator that the interactants recognise the SKS. The following speech signal demonstrates this fact.

\section{Excerpt 5}

Adjutant: Shouuldeeered arms!

They respond briskly to this order by clasping their rifles with their right hands across their shoulder. Also, the Review Officer grants permission to the Parade Commander to carry on with the parade through nodding. The Parade commander understands this, and act appropriately as he shares similar knowledge with the Review Officer. 


\subsection{Shared Knowledge of Professional Heroism (SKPH)}

Shared contextual belief based on the Shared Knowledge of Professional Heroism is also acted upon by the Nigerian soldiers in their discourse. As observed in the data, this shared belief is situated in the Armed Forces Remembrance Day celebration which is the day set aside in Nigeria to commemorate the military personnel (known as the fallen heroes) who were maimed, or died during active service for their fatherland. In this regard, three main categories of shared beliefs have been identified in the data; they are guns shot reference, narrated reference and instrument based sound.

\subsubsection{Instrument-based Sound}

Unlike the functions that instrument-based sound that manifests under the shared knowledge of signals, the instrument-based sound distinguished here relate to Armed-Forces Remembrance Day celebration in Nigeria. Consequently, drum and trumpet eulogizing the deceased soldiers and invoking a sense of sympathy in the audience are brought into play during the remembrance of the fallen heroes. This is a universal knowledge shared by the participants. The basis for the utilisation of the Instrument Based Sound is to honour, as well as mark the remembrance of the soldiers who lost their lives, or were maimed during active service for their fatherland. The Band Corps assume a shared ground projected through the instrumentality of sound involving drum beating, and trumpeting, which are marked by intermittent sonority. The songs which are rendered below in Yoruba in honour of the deceased soldier reflecting the SKPH are predominantly thanksgiving and praise songs unto God.

\section{Excerpt 6}

Band Corps: (Relay songs through band and trumpet) Ose o Jesu; a o ma yin o. O se o Jesu, a o ma yin o; baba gbo' pe ta muwa fun o... O mu wa de'le ogo, omuwa dele ogo ... (Appendix:5)

The song above, relayed by the Band Corps, laden with emotion, through the instrument based sound, is a praise song, thanking God and imploring Him to repose the souls of the departed heroes and accept them into His kingdom. That the Band Corps do not render the song orally indicates that, they are acting on the assumption that the participants can interpret the import of the song if relayed through the instrumentality of drum and trumpet as it is connected with the death of departed soldiers that they come to commemorate. Reinforcing the understanding of the participants is the knowledge of the Yoruba language through which the song is rendered.

The relay of these songs through the medium of drum and trumpet indicates that the Band Corps assume a shared belief with the audience. The participants at the event, especially the soldiers, appear in pensive and morose outlook when the sound is relayed, implying that they share similar belief with the Band Corps with respect to the message they are using the sound instrument to communicate in respect of the falling heroes. The Band Corps also assume a shared ground projected through the use of trumpet (without band) eulogising the deceased soldiers as well as invoking their spirit. That the participants share similar belief is confirmed by their morose and sober state, as they are seen bowing their heads reflectively.

\subsubsection{Verbalised Referent}

This is otherwise known as gun shot referent. It is a referent carried out through oral speech by the Parade Commander at the Armed Forces Remembrance Day. Ordering the soldiers to pay their last respect to the deceased, he makes a reference to three-gun salute to be shot in honour of the dead soldiers; hence :

\section{Excerpt 7}

\section{P.C: $\quad$ Three-gun salute to the fallen heroes}

Soldiers: Respond by shooting to the air thrice (Appendix: 5)

In the example above, the participants share the knowledge of professional heroism connected to the tribute paid to the dead soldiers. The addressor, based on this shared background, commands the soldiers to shoot thrice into the air by saying Three-gun salute to the fallen heroes through which the SKPH is revealed. By the pronouncement of the fallen heroes, the P.C assumes a shared belief with his audience that the falling heroes refer to the deceased soldiers and not just any mortal being. This causes them to respond by shooting thrice into the air in honour of the dead soldiers which is a mark of respect bestowed on the deceased soldiers.

\subsubsection{Narrated Referent}

This is the referent that is carried out through oral speech, alluding to the contribution of deceased solders to Nigeria in the aspect of security during their lifetime, and the circumstances that cause their demise. This type of referent is done by the cantonment clergies. Given the common ground they share with the participants at the occasion of the 
Armed-Forces Remembrance Day, the clergies narrated how soldiers fought the Civil War and how some of them died in the process. Appreciating this supreme sacrifice paid by the deceased soldiers in a bid to keep Nigeria one, they, therefore, pray for the departed soldiers. This type of referent is illustrated in the excerpt below:

\section{Excerpt 8}

Clergy: Some 65 years a go, there was a second world war in which

some Nigerians participated, and some of them perished. There was about 40 years ago, Civil War in this country where Nigerians participated and they were dying. Oh lord father, we are saying that members of Armed Forces are laying down their precious lives for others to have peace, for others to live. Today. Oh God! we are asking you to grant them eternal rest. May they be forgiven of any wrongdoing and granted them eternal rest. May those they would have provided for... and pay better attention for their welfare. We ask this through our Lord Jesus Christ. In the Name of the Father, the Son and the Holy Spirit.

In the excerpt above, the clergy bases his speech on the knowledge the participants have about the situation connected with the death of some soldiers. By making reference to the Civil War and World War in which some Nigerians soldiers took part and perished, he assumes that the participants share the same knowledge with him, hence does not need to make a lengthy explanation concerning the spatial or temporal setting: mentioning where and how the two wars actually took place. The abridged reference he made to the period that the wars took place also reinforces the shared belief assumption between the participants; hence, quoting the exact days, month and year that the two wars took place seems irrelevant. The words perished and dying indicate that these soldiers fought gallantly and lost their lives. The Clergy's speech, members of Armed Forces are laying down their precious lives for others to have peace, for others to live, implies that they died because of the interest they have in the survival of the citizens of their country, which is the reason that calls for their remembrance every year. The clergy is saying all these with the assumption that the knowledge of all he is saying is shared by the participants. The sharing of this knowledge is confirmed by the sombre and morose look of everybody (including the civilians present at the occasion), and that rightly indicates the SKPH. Ultimately, he prays to God to grant them eternal rest, and to provide for the family that they left behind. The choice of In the Name of the Father, the Son and the Holy Spirit implies that he is a Christian clergy, and every religious denomination, including Islam, shares this knowledge.

This is followed by the Nigerian National Anthem, which also presupposes that the celebration is in connection with the Nigerian soldiers that died during active service.

\section{Conclusion}

This paper has examined the contextual features that are projected in inter-brigade parade competition, and Armed-Forces Remembrance Day parades. These contextual features constitute various beliefs that are shared and acted upon by soldiers for the production and effective interpretation of verbal exchange of parade talks among soldiers. Consequently, the understanding and sharing of these features are capable of facilitating access to army parade interactions in Nigeria.

\section{References}

. (1953). Oral Gardens and their Magic. London: Allen and Unwin. II.

(1994). An Introduction to Functional Grammar. (2 ${ }^{\text {nd }}$ ed.). London: Edward Arnold.

. (1978). Explorations in the Functions of language. London: Edward Arnold.

(1995). An Introduction to Functional Grammar. London: Edward Arnold.

Amafah, J.F. (1990). The English language in the Nigerian Army: Situational and Linguistic Analysis. A Ph.D. Thesis in the Department of English. University of Ibadan.

Babatunde, S. (2006). A speech act analysis of Christian religious speeches. Style in religious communication in Nigeria. A. Odebunmi and A.O. Babajide. Eds. Muenchen: LinCOM Gmb. 48-84.

Bach, K. \& Harnish, R.M. (1979). Linguistic Communication and Speech acts. Massachusets:MIT Press.

Halliday, et al. (1964). The Linguistic Sciences and Language Teaching. London: Longman.

Halliday, M.A.K. (1961). Categories of the Theory of Grammar: Halliday Systems and Function in Language in G. Kress. Ed. Oxford: Oxford University Press. 52-72. 
Halliday, M.A.K \& Hassan, R. (1991). Language, Context and Text: Aspects of Language in a Social-Semiotic Perspective. ( $2^{\text {nd }}$ ed.) Oxford: Oxford University Press.

Hawryluk, N. (2010). Military Linguistics: Russian in the Red/Soviet Army. Journal of Military and Strategic Studies, Vol.12, issue 3. Retrieved $15^{\text {th }}$ February from http://Jmss.org/Jmss/316-337.

Malinowski, B. (1923/46). The problem of meaning in primitive languages. Supplement to Ogden, C.K. \& Richards in I.A. The Meaning of Meaning.(8th edition, 1946). New York: Harcourt Brace and World. Pp296-336.

Odebunmi, A. (2006). Meaning in English: An Introduction. Ogbomosho: Critical Sphere.

Widdowson, H.G. (1996). An approach to stylistics analysis. The stylistics reader: from Roman Jakobson to the present in J.J. Weber (ed.): New York. Pp 138-148.

Woodward, R. (2004). Discourse of gender in the contemporary British Army in Sage Journal of Armed Forces and Society Winter. 30.2. 279-301. Retrieved 28/4/2014 from http//www.google.com. 